\title{
Clinicopathological Manifestations and Immune Phenotypes in Adult-Onset Immunodeficiency with Anti-Interferon-y Autoantibodies
}

\author{
Yi-Chun Chen \\ Kaohsiung Chang Gung Memorial Hospital \\ Shao-Wen Weng \\ Kaohsiung Chang Gung Memorial Hospital \\ Jing-Ya Ding \\ Chang Gung University \\ Chen-Hsiang Lee \\ Kaohsiung Chang Gung Memorial Hospital \\ Cheng-Lung Ku \\ Chang Gung University \\ Wen-Chi Huang \\ Kaohsiung Chang Gung Memorial Hospital

\section{Huey-Ling You} \\ Kaohsiung Chang Gung Memorial Hospital and Chang Gung University College of Medicine \\ Wan-Ting Huang ( $\sim$ huangwanting5@gmail.com ) \\ Chang Gung Memorial Hospital Kaohsiung Branch https://orcid.org/0000-0001-6442-3713
}

\section{Research Article}

Keywords: adult-onset immunodeficiency, anti-interferon-y autoantibody, lymphocyte subpopulations, cytokine production

Posted Date: September 21st, 2021

DOI: https://doi.org/10.21203/rs.3.rs-562260/v2

License: (c) (i) This work is licensed under a Creative Commons Attribution 4.0 International License. Read Full License

Version of Record: A version of this preprint was published at Journal of Clinical Immunology on January 28th, 2022. See the published version at https://doi.org/10.1007/s10875-022-01210-y. 


\section{Abstract \\ Purpose}

Anti-interferon (IFN)- $y$ autoantibodies (anti-IFN- $\gamma$ Abs) is an emerging adult-onset immunodeficiency syndrome. Immune dysfunction in this distinct disorder remains to be clarified.

\section{Methods}

We prospectively collected blood samples of 20 patients with anti-IFN-y Abs and 40 healthy normal subjects. The percentages of lymphocyte subpopulations, most relevant to T, B, and NK cells, and the percentages of stimulated lymphocytes with cytokine production were assessed using eight-color flow cytometry. The results were adjusted to age and absolute lymphocyte counts.

\section{Results}

Most (85\%) patients presented nontuberculous mycobacterial infection. Skin lesions were predominantly manifested by neutrophilic dermatoses. The involved lymph nodes had granulomatous inflammation, except $22.2 \%$ showing atypical lymphoid hyperplasia without granuloma formation. The percentages of CD $4+T$ cells and non-activated subpopulations (recent thymic emigrants and naïve subtypes) decreased significantly with increased expression of activation markers and polarization to differentiated cells. The percentage of NK cells increased, but that of two major NK subpopulations, CD56 ${ }^{\text {bright }}$ and CD56 + CD16 + subsets decreased. Furthermore, the expression of NKp30 and NKp46 decreased with increased CD57 expression. Intracellular cytokine production of the lymphocyte subpopulations were significantly low in the patients compared with the control group.

\section{Conclusion}

We conclude that the immune system in patients with anti-IFN-Y Abs could be exhausted, contributing to the distinct clinicopathologic features.

\section{Introduction}

Adult-onset immunodeficiency due to anti-interferon (IFN)-y autoantibodies (anti-IFN-y Abs) is a distinct disorder, recently emerging in Southeast Asia [1, 2]. Thus far more than 600 patients with anti-IFN-ץ Abs have been described [3, 4]. Almost all patients are adults aged 30-70 years with no sex predominance [1, 3]. Neutralizing anti-IFN- $\gamma$ Abs are responsible for the increased susceptibility to infections of nontuberculous mycobacteria (NTM) and intracellular pathogens. The lymph nodes were most commonly involved organ followed by the skin [5]. Besides direct infections, reactive conditions such as skin manifestation were frequent, with reactive skin disorders, mostly neutrophilic dermatoses, reported in $82 \%$ of the patients [6]. Early diagnosis of the disease is difficult owing to the protean manifestations in apparently immunocompetent hosts and the absence of standard laboratory assays $[7,8]$. Patients may require long-term antimycobacterial therapy because of chronic infections and high recurrence rates, even after remission $[9,10]$.

IFN-y plays a critical regulatory role in macrophage-mediated killing and granuloma formation in response to intracellular pathogen infection. Over the past one and a half decades, anti-IFN- $\gamma$ Abs have been associated with disseminated NTM and other opportunistic infections, including those caused by Salmonella species, Talaromyces marneffei [11], and varicellazoster virus [4]. Titers of anti-IFN-y Abs may reflect disease activity [9]; however, the pathogenesis of anti-IFN-y Abs associated with immunodeficiency syndrome remains elusive. A previous study reported that the presence of anti-IFN-y Abs 
had immunosuppressive effects in both innate and adaptive immunity. This is done by blocking IFN-y activated STAT1 activation, IRF1 transactivation, and the production of chemokines and cytokines [12], putting a stop to IFN- $y$-induced immunomodulation and antimicrobial activities.

Some studies have highlighted alterations in lymphocyte subpopulations in patients with anti-IFN-y Abs. The percentages of $T$ cells and naïve subsets decreased, while the number of NK cells increased $[1,13]$. Decreased abilities of lymphocyte subpopulations to produce TNF-a, IFN- $\gamma$, and IL-2 were reported [12, 14]; however, a comprehensive analysis of the lymphocyte subpopulations and activities is limited. In this study, we have not only described the clinicopathologic features of 20 patients with anti-IFN-y Abs but analyzed the most relevant T, B, and NK cell subpopulations using eight-color flow cytometry. The percentages of stimulated lymphocyte subsets producing cytokines were evaluated. Our results suggest that the immune dysfunction of adult-onset immunodeficiency due to anti-IFN- $\gamma$ Abs may be associated with immune exhaustion.

\section{Material And Methods Study population}

Twenty patients diagnosed with anti-IFN-y Abs at the Chang Gung Memorial Hospital in Kaohsiung, Taiwan were selected. Anti-IFN-y Abs in plasma was determined using methods described in supplementary. Absorbance was read at a wavelength of $405 \mathrm{~nm}$ (Supplementary Fig. 1). All patients were HIV-negative. To reflect the immune status of patients, we classified the patients into two groups based on their clinical conditions. One group had an active infection or continued antimicrobial therapy within 3 months before the experiments (active cases) and the other recovered from the infection with discontinued therapy (resolved cases). Forty healthy normal subjects with no evidence of immunosuppression were included as a control group. The clinical data of all enrolled patients were collected. The hematoxylin and eosin-stained sections obtained at the time of diagnosis and repeats were reviewed by the pathologist. This study was approved by the Ethics Committee of the Chang Gung Memorial Hospital, Kaohsiung, Taiwan, in accordance with the Declaration of Helsinki (IRB201901509B0C501). Written informed consent was obtained from all subjects prior to enrollment.

\section{Lymphocyte subpopulations using flow cytometric analysis}

EDTA-anticoagulated whole blood samples were collected for the flow cytometry study. A staining volume of $100 \mu \mathrm{L}(2$ to 3 $x 10^{6}$ cells) peripheral blood mononuclear cells (PBMCs) separated using centrifugation was incubated with an antibody cocktail (BD Biosciences, Heidelberg, Germany) (Supplementary Table 1). The eight-color staining panels for the lymphocyte subpopulations were set and analyzed as previously reported [15]. The panels differentiated the subsets from the lymphocyte populations to assess (1) the general lymphocyte overview; (2) B cell subpopulations; (3) CD4 + T cell subpopulations; (4) CD8 + T cell subpopulations; (5) regulatory T cell subpopulations; (6) recent thymic emigrants (RTEs); (7) NK cell subpopulations; and (8) NK cell activation markers. After incubation for $20 \mathrm{~min}$ at room temperature $\left(23^{\circ} \mathrm{C}\right)$ in the dark, the red blood cells (RBCs) were lysed using lysis buffer (BD Biosciences) for 10 min. Following centrifugation and washing with phosphate buffered saline (PBS), the cells were fixed with $200 \mu \mathrm{L}$ PBS containing $1 \%$ formaldehyde and stored at $4^{\circ} \mathrm{C}$ in a dark chamber until flow cytometry analysis. We used a FACS Canto II flow cytometer (BD Biosciences) equipped with three lasers (405 $\mathrm{nm}$ violet laser, $488 \mathrm{~nm}$ blue laser, and $647 \mathrm{~nm}$ red laser) for data acquisition and the FACS DIVA software (BD Biosciences) for data analysis.

\section{Cytokine secretion assay}

The cytokine secretion ability of $B, T$, and NK cells was detected using flow cytometry. Briefly, we diluted $100 \mu \mathrm{L}$ of PBMCs with $400 \mu \mathrm{L}$ of IMDM (Gibco-BRL, Grand Island, NY, USA) in polystyrene tubes, and then stimulated the cells with or without the leukocyte activation cocktail (BD GolgiPlug ${ }^{\mathrm{TM}}$, Germany) for $4 \mathrm{~h}$ at $37{ }^{\circ} \mathrm{C}$ in $5 \% \mathrm{CO}_{2}$. After stimulation, fluorochromeconjugated lineage antibodies (Supplementary Table 1) were added and incubated for $15 \mathrm{~min}$ at room temperature (RT) 
followed by lysis of the RBCs. The cells were then fixed and permeabilized with $250 \mu \mathrm{L}$ of Cytofix/Cytoperm (BD, Germany) at RT for 20 mins. After staining with fluorochrome-conjugated cytokine antibodies (Supplementary Table 1) for 20 min at $\mathrm{RT}$, the cell pellets were washed and resuspended in $200 \mu \mathrm{L}$ PBS. The FACS Canto II flow cytometer (BD Biosciences) and the FACS DIVA software (BD Biosciences) were used for data acquisition and analysis, respectively. The gated lymphocyte populations were further assessed for intracellular cytokine-producing cells. The levels of intracellular cytokines after stimulation were quantitatively determined from the percentage of lymphocytes with higher fluorescence intensity than cells without treatment.

\section{Statistical analysis}

All statistical analyses were performed using SPSS 17.0 for Windows (SPSS Inc. Chicago, IL). The Chi-square test, Fisher's exact test, and $t$-test were used to compare the data between the two groups. The comparisons between three groups were performed using one-way analysis of variance (ANOVA), followed by Fisher's Least Significant Difference (LSD) for post hoc comparisons. A two-sided test of significance was used and $P<0.05$ was considered statistically significant.

\section{Results}

\section{Clinical features}

The mean age was 61.4 years (range: $44.8-82.5$ years) in the case group and 53.2 years (range: $25.7-69.9$ years) in the control group. The levels of C-reactive protein in the active cases were higher than those in the resolved cases (45.8 \pm 18.8 $\mathrm{mg} / \mathrm{L}$ vs. $12.3 \pm 3.9 \mathrm{mg} / \mathrm{L}, P=0.006)$. Table 1 summarizes the pertinent clinical presentation. Eight-five percentage (17/20) of patients had NTM infection, with three patients $(3 / 17,17.6 \%)$ infected by more than one species. The most frequently isolated NTM was Mycobacterium abscessus. Case 8 had obstruction and perforation of the jejunum due to a diffuse large B cell lymphoma (DLBCL) (15 months after diagnosis). Skin manifestations were found in 14 patients (70\%), including reactive skin conditions and infectious diseases. Cutaneous infection due to Listeria monocytogenes was found in Case 19. The skin featured acute onset of generalized edematous erythema with nonfollicular sterile pustules. 
Table 1

Clinicopathologic features of the patients with anti-IFN- autoantibodies

\begin{tabular}{|c|c|c|c|c|c|c|c|}
\hline Case & Age/sex & $\begin{array}{l}\text { Associated } \\
\text { infection }\end{array}$ & $\begin{array}{l}\text { Site of } \\
\text { involvement }\end{array}$ & $\begin{array}{l}\text { Pattern of } \\
\text { dermatosis }\end{array}$ & $\begin{array}{l}\text { Histology of } \\
\text { LN/detection } \\
\text { of } \\
\text { mycobacterium }\end{array}$ & $\begin{array}{l}\text { Antibiotic } \\
\text { cessation } \\
(\mathrm{m})^{\mathrm{a}}\end{array}$ & $\begin{array}{l}\text { Follow- } \\
\text { up } \\
\text { duration } \\
\text { (m) }\end{array}$ \\
\hline 1 & $52 / F$ & $\begin{array}{l}\text { Disseminated } M \text {. } \\
\text { abscessus } \\
\text { infection, } \\
\text { disseminated } M \text {. } \\
\text { chimaera } \\
\text { intracelluare } \\
\text { infection, } \\
\text { Salmonella sp. } \\
\text { infection }\end{array}$ & $\begin{array}{l}\text { Blood, lung, } \\
\text { vertebra, soft } \\
\text { tissue and } \\
\text { breast }\end{array}$ & NA & NA & - & 97 \\
\hline 2 & $45 / F$ & $\begin{array}{l}\text { Pulmonry } \\
\text { Fonsecaea sp } \\
\text { infection, } \\
\text { Salmonella } \\
\text { choleraaesuis } \\
\text { bacteremia, } \\
\text { disseminated } M \text {. } \\
\text { abscessus } \\
\text { infection }\end{array}$ & $\begin{array}{l}\text { Blood, lymph } \\
\text { node, skin, } \\
\text { bone and soft } \\
\text { tissue }\end{array}$ & $\begin{array}{l}\text { Direct skin and } \\
\text { soft tissue } \\
\text { infection }\end{array}$ & NGI/- & - & 55 \\
\hline 3 & $71 / M$ & $\begin{array}{l}\text { Disseminated } M \text {. } \\
\text { chimaera- } \\
\text { intracellulare } \\
\text { infection }\end{array}$ & $\begin{array}{l}\text { Lung, lymph } \\
\text { node, skin and } \\
\text { soft tissue }\end{array}$ & $\begin{array}{l}\text { Direct skin and } \\
\text { soft tissue } \\
\text { infection }\end{array}$ & LH/- & - & 53 \\
\hline 4 & $70 / \mathrm{M}$ & $\begin{array}{l}\text { Salmonella sp. } \\
\text { infection, } M \text {. } \\
\text { abscessus } \\
\text { lymphadenitis, } \\
\text { Burkholderia } \\
\text { gladioli } \\
\text { bacteremia and } \\
\text { deep neck } \\
\text { infection }\end{array}$ & $\begin{array}{l}\text { Blood, lung, } \\
\text { lymph node } \\
\text { and soft } \\
\text { tissue }\end{array}$ & $\begin{array}{l}\text { Exanthematous } \\
\text { pustulosis }\end{array}$ & $\mathrm{SN} /+$ & $+(7)$ & 46 \\
\hline 5 & $45 / M$ & $\begin{array}{l}\text { Disseminated } \\
\text { tuberculosis, } \\
\text { disseminated } M \text {. } \\
\text { chimaera- } \\
\text { intracellular group } \\
\text { infection, } \\
\text { Salmonella } \\
\text { enterica } \\
\text { serogroup D } \\
\text { bacteremia }\end{array}$ & $\begin{array}{l}\text { Blood, lung, } \\
\text { bone marrow, } \\
\text { spine, soft } \\
\text { tissue }\end{array}$ & NA & LH/- & - & 36 \\
\hline 6 & $61 / F$ & $\begin{array}{l}\text { Disseminated } M \text {. } \\
\text { abscessus } \\
\text { infection }\end{array}$ & $\begin{array}{l}\text { Lymph node } \\
\text { and brain }\end{array}$ & NA & $\begin{array}{l}\mathrm{LH} /-, \mathrm{SN} /+ \\
\mathrm{NGI} /+\end{array}$ & - & 48 \\
\hline $\begin{array}{l}7 \\
{[10} \\
26]\end{array}$ & $65 / F$ & $\begin{array}{l}\text { Salmonella sp. } \\
\text { infection, } \\
\text { disseminated } M \text {. } \\
\text { avium complex } \\
\text { infection }\end{array}$ & $\begin{array}{l}\text { Lung, bone, } \\
\text { soft tissue, } \\
\text { and bone } \\
\text { marrow }\end{array}$ & NA & NA & $+(71)$ & 125 \\
\hline
\end{tabular}




\begin{tabular}{|c|c|c|c|c|c|c|c|}
\hline \multicolumn{8}{|l|}{$Y$} \\
\hline 8 & $75 / M$ & $\begin{array}{l}\text { M. hassiacum } \\
\text { infection, M. } \\
\text { parascrofulaceum } \\
\text { infection, } M \text {. } \\
\text { farcinogenes- } \\
\text { senegalense } \\
\text { infection }\end{array}$ & $\begin{array}{l}\text { Lung, bone, } \\
\text { soft tissue, } \\
\text { bone marrow } \\
\text { and lymph } \\
\text { node }\end{array}$ & $\begin{array}{l}\text { Exanthematous } \\
\text { pustulosis }\end{array}$ & NA & $+(2)$ & 39 \\
\hline $\begin{array}{l}9 \\
{[10]}\end{array}$ & $52 / F$ & $\begin{array}{l}\text { Salmonella } \\
\text { enterica } \\
\text { serogroup D } \\
\text { bacteremia, } M \text {. } \\
\text { intracellulare } \\
\text { infection }\end{array}$ & $\begin{array}{l}\text { Blood, } \\
\text { nasophargynx, } \\
\text { lung, lymph } \\
\text { node, skin soft } \\
\text { tissue }\end{array}$ & $\begin{array}{l}\text { Exanthematous } \\
\text { pustulosis, } \\
\text { direct skin and } \\
\text { soft tissue } \\
\text { infection }\end{array}$ & NGI/- & $+(11)$ & 89 \\
\hline $\begin{array}{l}10 \\
{[10]}\end{array}$ & $73 / F$ & $\begin{array}{l}\text { Disseminated } M \text {. } \\
\text { intracelluare } \\
\text { infection }\end{array}$ & $\begin{array}{l}\text { Lung, skin, } \\
\text { lymph node, } \\
\text { spine, bone } \\
\text { marrow }\end{array}$ & NA & ALH/- & $+(48)$ & 97 \\
\hline 11 & $62 / F$ & $\begin{array}{l}\text { Salmonella } \\
\text { enterica } \\
\text { serogroup D } \\
\text { infection, } M \text {. } \\
\text { fortuitum } \\
\text { lymphadenitis } \\
\text { infection }\end{array}$ & $\begin{array}{l}\text { Lymph node, } \\
\text { brain }\end{array}$ & NA & $\mathrm{NGI} /+$ & $+(11)$ & 73 \\
\hline 12 & $48 / F$ & $\begin{array}{l}\text { M. abscessus } \\
\text { infection, } M \text {. } \\
\text { kansasii infection }\end{array}$ & $\begin{array}{l}\text { Lymph node, } \\
\text { spine }\end{array}$ & $\begin{array}{l}\text { Exanthematous } \\
\text { pustulosis, } \\
\text { erythema } \\
\text { nodosum and } \\
\text { erythema } \\
\text { induratum }\end{array}$ & $\mathrm{NGI} /+$ & $+(12)$ & 65 \\
\hline 13 & $65 / M$ & $\begin{array}{l}\text { Disseminated } M \text {. } \\
\text { abscessus } \\
\text { infection }\end{array}$ & $\begin{array}{l}\text { Lymph node, } \\
\text { spine }\end{array}$ & NA & $\mathrm{ALH} /+, \mathrm{SN} /+$ & - & 44 \\
\hline 14 & $58 / F$ & $\begin{array}{l}\text { Salmonella } \\
\text { enterica } \\
\text { serogroup B } \\
\text { bacteremia }\end{array}$ & Blood & NA & $\mathrm{ALH} /-$ & - & 33 \\
\hline 15 & $60 / F$ & $\begin{array}{l}\text { Salmonella sp. } \\
\text { bacteremia, M. } \\
\text { abscessus } \\
\text { infection }\end{array}$ & $\begin{array}{l}\text { Blood and } \\
\text { lymph node }\end{array}$ & NA & $\mathrm{NGI} /+$ & $+(6)$ & 11 \\
\hline 16 & $72 / \mathrm{M}$ & $\begin{array}{l}\text { M. intracelluare } \\
\text { infection }\end{array}$ & Lung & $\begin{array}{l}\text { Sweet's } \\
\text { syndrome }\end{array}$ & NA & $+(9)$ & 48 \\
\hline 17 & $56 / \mathrm{M}$ & $\begin{array}{l}\text { Disseminated } M \text {. } \\
\text { abscessus } \\
\text { infection }\end{array}$ & $\begin{array}{l}\text { Nasopharynx, } \\
\text { lymph node }\end{array}$ & $\begin{array}{l}\text { Erythema } \\
\text { nodosum }\end{array}$ & $\mathrm{NGI} /+$ & - & 15 \\
\hline $\begin{array}{l}18 \\
{[10,} \\
27]\end{array}$ & $66 / M$ & $\begin{array}{l}\text { Disseminated } M \text {. } \\
\text { abscessus } \\
\text { infection }\end{array}$ & Lymph node & $\begin{array}{l}\text { Sweet's } \\
\text { syndrome }\end{array}$ & $\mathrm{ALH} /+, \mathrm{NGI} /-$ & $+(51)$ & 90 \\
\hline 19 & $82 / F$ & $\begin{array}{l}\text { Listeria } \\
\text { monocytogenes } \\
\text { infection, } \\
\text { Salmonella } \\
\text { choleraesuis } \\
\text { bacteremia }\end{array}$ & $\begin{array}{l}\text { Blood and } \\
\text { skin }\end{array}$ & $\begin{array}{l}\text { Exanthematous } \\
\text { pustulosis }\end{array}$ & NA & $+(6)$ & 13 \\
\hline
\end{tabular}




\begin{tabular}{|l|l|}
\hline Y \\
\hline $20 \quad 48 / \mathrm{F}$ & $\begin{array}{l}\text { Salmonella sp. } \\
\text { infection }\end{array}$ \\
$\begin{array}{l}\text { ALH, atypical lymphoid hyperplasia; M., mycobacterium; m, months; NA, not available; NGI, necrotizing granulomatous } \\
\text { inflammation; SN, suppurative necrosis; sp., species }\end{array}$ \\
athe period between ceasing antimicrobial agents and blood sampling \\
Cases 7, 9, 10, and 18 have previously been described. References were cited.
\end{tabular}

\section{Pathological features}

Figure 1 depicts the histopathological features of the skin and lymph nodes, and the case with malignant lymphoma. Skin biopsies were available in 10 (50\%) patients, seven with reactive skin disorders, two (Cases 2 and 3 ) with granulomatous dermatoses, and one (Case 9) with reactive lesions followed by granulomatous inflammation. Reactive lesions were mostly neutrophilic dermatoses such as exanthematous pustulosis, Sweet syndrome, and panniculitis. A total of 18 lymph nodes in 14 patients were available. Of these, eight samples (44.4\%) showed necrotizing granulomatous inflammation, while three samples (16.7\%) showed suppurative necrosis, whereas four (22.2\%) samples had atypical lymphoid hyperplasia featuring a histiocytic response without granuloma formation. NTM infection was demonstrated using either acid-fast staining or culture in two patients (Cases 13 and 18) with atypical lymphoid hyperplasia. M. abscessus was the most frequently isolated species from the lymph nodes rather than from other anatomic locations $(7 / 8,87.5 \%$ vs. $2 / 9,22.2 \% ; P=0.015)$; whereas, $M$. avium complex was the predominant species isolated from non-nodal lesions. Case 8 had a diffuse large B-cell lymphoma in the jejunum featuring transmural involvement of the bowel wall by large-sized lymphoma cells.

\section{Distribution of subpopulations of peripheral blood lymphocytes}

The flow cytometry gating strategy and representative immunophenotyping of lymphocyte subsets is shown in the Supplementary Fig. 2. Table 2 summarizes the comparison of the lymphocyte subpopulations between the groups based on flow cytometry data. The mean age of the patients was significantly higher than that of the healthy subjects. The percentages of constitutive T and NK cell subsets were significantly different between the case and control groups (Fig. 2). The case groups showed significantly lower levels of CD $4+T$ cells and non-activated subpopulations (RTEs and naïve subtypes). The ratios of CD $4+\mathrm{RTE} / \mathrm{CD} 4+$ naïve T cells $(0.47 \pm 0.12$ in the active cases; $0.56 \pm 0.18$ in the resolved cases; $0.62 \pm 0.14$ in the controls, $P=0.013)$ and CD $8+$ RTE/CD $8+$ naïve T cells $(0.86 \pm 0.14$ in the active cases; $0.88 \pm 0.09$ in the resolved cases; $0.95 \pm 0.05$ in the controls, $P=0.006$ ) were significantly lower in the patients than in the controls. In contrast, those relevant to activated T cell subpopulations showed significant increases in percentages. The NK cell subsets indicated that the case groups had lower levels of NK cells with either cytotoxic function or expression of Nkp30 and Nkp46, while levels of CD57 + NK cells were significantly higher compared to those in the control group. In addition, significant differences were present between the active and resolved cases. The mean percentages of CD $56+$ CD $16+$ NK cells $(71.6 \pm 8.6$ vs. $79.5 \pm 11.4, P=0.012)$ and $\mathrm{CD} 4+\mathrm{TCM}(10.9 \pm 11.6$ vs. $17.4 \pm 6.1, P=0.026)$ were lower; nevertheless, the levels of CD4 + CD38 + HLA-DR + T cells (30.7 \pm 15.5 vs. $13.8 \pm 11.4, P<0.001)$, CD $4+$ CCR6 + T cells (45.0 \pm 14.6 vs. $33.9 \pm 10.4, P=0.007), \mathrm{CD} 8+\mathrm{CD} 38+\mathrm{HLA}-\mathrm{DR}+(36.2 \pm 18.7$ vs. $25.5 \pm 14.1, P=0.041)$, and HLA-DR + Treg cells $(52.7 \pm 21.9$ vs. $23.8 \pm 15.1, P<0.001)$ were higher in the active cases than in the resolved cases. 
Table 2

Lymphocytes subpopulations in the patients with anti-IFN- autoantibodies and healthy controls

\begin{tabular}{|c|c|c|c|c|}
\hline \multirow[t]{3}{*}{ Variable } & \multicolumn{3}{|l|}{ Groups } & \multirow[t]{3}{*}{$P$ value } \\
\hline & Active cases & Recovered cases $(\mathrm{N}=10)$ & Controls $(\mathrm{N}=40)$ & \\
\hline & $(\mathrm{N}=10)$ & & & \\
\hline Age (yr) & $57.7 \pm 10.5$ & $65.1 \pm 10.3^{a}$ & $53.2 \pm 8.0^{\mathrm{a}}$ & 0.001 \\
\hline Absolute lymphocyte count $\left(\times 10^{2}\right.$ cells $\left./ \mu \mathrm{L}\right)$ & $20.7 \pm 7.7$ & $21.9 \pm 9.2$ & $20.1 \pm 7.6$ & 0.823 \\
\hline T cells (\% lymphocytes) & $53.7 \pm 13.8^{b}$ & $51.8 \pm 12.7^{\mathrm{a}}$ & $65.4 \pm 10.2^{\mathrm{ab}}$ & 0.001 \\
\hline$\alpha / \beta$ T cells ( $\%$ T cells) & $93.7 \pm 3.8$ & $93.9 \pm 4.9$ & $91.0 \pm 5.4$ & 0.139 \\
\hline үઠ T cells (\% T cells) & $4.8 \pm 4.1$ & $4.8 \pm 4.7$ & $8.1 \pm 5.3$ & 0.061 \\
\hline CD4 + T cells (\% T cells) & $23.4 \pm 7.9^{b}$ & $23.2 \pm 6.3^{a}$ & $34.9 \pm 7.3^{\mathrm{ab}}$ & $<0.001$ \\
\hline CD45RA + CD62L + CD31+ (\% CD4 + cells $)$ & $7.8 \pm 8.4^{b}$ & $7.8 \pm 5.7^{\mathrm{a}}$ & $25.6 \pm 9.4^{\mathrm{ab}}$ & $<0.001$ \\
\hline Naïve (\% CD4 + cells) & $11.8 \pm 10.9^{b}$ & $10.7 \pm 5.8^{\mathrm{a}}$ & $32.1 \pm 12.9^{\mathrm{ab}}$ & $<0.001$ \\
\hline CD38 + HLA-DR+ (\% CD4 + cells) & $30.7 \pm 15.5^{\mathrm{bc}}$ & $13.8 \pm 11.4^{\mathrm{ac}}$ & $5.0 \pm 2.8^{\mathrm{ab}}$ & $<0.001$ \\
\hline TCM (\% CD4 + cells) & $10.9 \pm 4.2^{\mathrm{bc}}$ & $17.4 \pm 6.1^{\mathrm{c}}$ & $16.7 \pm 6.8^{b}$ & 0.031 \\
\hline TEM (\% CD4 + cells) & $70.0 \pm 14.0^{\mathrm{b}}$ & $63.8 \pm 9.6^{\mathrm{a}}$ & $39.0 \pm 12.4^{\mathrm{ab}}$ & $<0.001$ \\
\hline TE (\% CD4 + cells) & $4.1 \pm 7.7$ & $3.0 \pm 1.8$ & $6.3 \pm 5.5$ & 0.193 \\
\hline CCR5+ (\% CD4 + cells $)$ & $47.2 \pm 14.9^{b}$ & $39.9 \pm 11.6^{\mathrm{a}}$ & $18.9 \pm 10.3^{\mathrm{ab}}$ & $<0.001$ \\
\hline CCR3+ (\% CD4 + cells $)$ & $14.9 \pm 18.0^{b}$ & $9.4 \pm 13.9$ & $3.0 \pm 4.1^{\mathrm{b}}$ & 0.002 \\
\hline CCR6+ (\% CD4 + cells $)$ & $45.0 \pm 14.6^{\mathrm{bc}}$ & $33.9 \pm 10.4^{\mathrm{ac}}$ & $17.1 \pm 6.3^{\mathrm{ab}}$ & $<0.001$ \\
\hline CD8 + T cells (\% T cells) & $26.4 \pm 7.9$ & $24.8 \pm 8.4$ & $25.5 \pm 7.6$ & 0.893 \\
\hline CD45RA + CD62L + CD31+ (\% CD8 + cells $)$ & $5.7 \pm 6.0^{b}$ & $4.6 \pm 3.1^{\mathrm{a}}$ & $18.5 \pm 9.3^{\mathrm{ab}}$ & $<0.001$ \\
\hline Naïve (\% CD8 + cells) & $6.8 \pm 6.9^{b}$ & $6.2 \pm 4.2^{\mathrm{a}}$ & $23.6 \pm 12.4^{\mathrm{ab}}$ & $<0.001$ \\
\hline CD38 + HLA-DR+ (\% CD8 + cells) & $36.2 \pm 18.7^{b c}$ & $25.5 \pm 14.1^{\mathrm{ac}}$ & $15.8 \pm 8.1^{\mathrm{ab}}$ & $<0.001$ \\
\hline TCM (\% CD8 + cells) & $4.0 \pm 4.8^{b}$ & $3.8 \pm 4.3^{\mathrm{a}}$ & $1.8 \pm 1.2^{\mathrm{ab}}$ & 0.031 \\
\hline TEM (\% CD8 + cells) & $60.1 \pm 15.4^{b}$ & $59.5 \pm 9.7^{\mathrm{a}}$ & $43.0 \pm 14.6^{\mathrm{ab}}$ & $<0.001$ \\
\hline TE (\% CD8 + cells $)$ & $21.5 \pm 12.0$ & $22.1 \pm 11.8$ & $24.5 \pm 13.3$ & 0.751 \\
\hline TEM CCR5+ (\% CD8 + cells) & $37.0 \pm 18.5$ & $40.4 \pm 9.9^{a}$ & $28.8 \pm 11.2^{\mathrm{a}}$ & 0.017 \\
\hline TE CCR5+ (\% CD8 + cells) & $9.1 \pm 11.7$ & $9.0 \pm 5.2$ & $9.7 \pm 7.1$ & 0.945 \\
\hline Regulatory T (Treg) cells (\% T cells) & $6.2 \pm 3.3$ & $6.6 \pm 4.0$ & $5.0 \pm 1.4$ & 0.114 \\
\hline Naïve (\% Treg cells) & $17.3 \pm 9.4^{\mathrm{b}}$ & $21.0 \pm 13.6^{a}$ & $39.0 \pm 14.2^{\mathrm{ab}}$ & $<0.001$ \\
\hline
\end{tabular}




\begin{tabular}{|c|c|c|c|c|}
\hline \multicolumn{5}{|l|}{ Y } \\
\hline Memory (\% Treg cells) & $82.7 \pm 9.4^{b}$ & $79.0 \pm 13.6^{a}$ & $61.0 \pm 14.2^{\mathrm{ab}}$ & $<0.001$ \\
\hline HLA-DR+ (\% Treg cells) & $52.7 \pm 21.9^{b c}$ & $23.8 \pm 15.1^{\mathrm{ac}}$ & $14.4 \pm 4.2^{\mathrm{ab}}$ & $<0.001$ \\
\hline B cells (\% lymphocytes) & $9.3 \pm 5.7$ & $9.5 \pm 6.6$ & $8.7 \pm 3.5$ & 0.849 \\
\hline Transitional (\% B cells) & $2.7 \pm 2.3$ & $2.2 \pm 1.8$ & $2.5 \pm 1.3$ & 0.783 \\
\hline Naïve (\% B cells) & $61.8 \pm 23.4$ & $61.7 \pm 26.2$ & $68.4 \pm 13.4$ & 0.398 \\
\hline Non-switched memory (\% B cells) & $10.7 \pm 5.2$ & $8.1 \pm 3.3$ & $8.8 \pm 5.1$ & 0.448 \\
\hline Switched memory (\% B cells) & $7.5 \pm 7.3$ & $8.5 \pm 6.3$ & $12.2 \pm 6.1$ & 0.057 \\
\hline CD21^lowCD38^low (\% B cells) & $6.0 \pm 5.1$ & $6.8 \pm 4.9$ & $5.4 \pm 4.4$ & 0.672 \\
\hline Plasmablast (\% B cells) & $3.4 \pm 5.7$ & $1.6 \pm 1.4$ & $1.4 \pm 0.8$ & 0.076 \\
\hline Plasma cell (\% B cells) & $3.3 \pm 7.3$ & $2.1 \pm 2.7$ & $0.8 \pm 0.6$ & 0.087 \\
\hline NK cells (\% lymphocytes) & $36.1 \pm 15.7^{b}$ & $37.9 \pm 14.9^{a}$ & $24.5 \pm 10.8^{a b}$ & 0.002 \\
\hline CD56 + bright (\% NK cells) & $2.2 \pm 1.4^{b}$ & $2.3 \pm 1.1^{a}$ & $4.2 \pm 2.6^{\mathrm{ab}}$ & 0.010 \\
\hline CD56 + CD 16+ (\% NK cells $)$ & $71.6 \pm 8.6^{b c}$ & $79.5 \pm 11.4^{\mathrm{ac}}$ & $92.8 \pm 4.6^{\mathrm{ab}}$ & $<0.001$ \\
\hline Nkp30 (\% NK cells) & $22.7 \pm 13.2^{b}$ & $22.1 \pm 10.2^{\mathrm{a}}$ & $51.2 \pm 14.8^{\mathrm{ab}}$ & $<0.001$ \\
\hline Nkp44 (\% NK cells) & $0.7 \pm 0.5$ & $0.6 \pm 0.4$ & $0.5 \pm 0.4$ & 0.187 \\
\hline Nkp46 (\% NK cells) & $12.8 \pm 6.5^{\mathrm{b}}$ & $13.0 \pm 6.1^{\mathrm{a}}$ & $42.3 \pm 14.2^{\mathrm{ab}}$ & $<0.001$ \\
\hline CD57+ (\% NK cells) & $79.3 \pm 8.8^{b}$ & $80.0 \pm 7.3^{\mathrm{a}}$ & $59.7 \pm 11.5^{\mathrm{ab}}$ & $<0.001$ \\
\hline \multicolumn{5}{|c|}{ Data presented in means \pm standard deviation } \\
\hline \multicolumn{5}{|c|}{ Small letters represent statistically significant differences among the groups (ANOVA and LSD) } \\
\hline TCM, central memory $\mathrm{T}$ cell; $\mathrm{TE}$, & $\Gamma \mathrm{EM}, \epsilon$ & emory $\mathrm{T} c$ & & \\
\hline
\end{tabular}

\section{Production of cytokines in lymphocyte subpopulations}

We then tested the production of intracellular cytokines of PBMCs that were free of autologous plasma to determine cellintrinsic functions. Expressions of TNF- $a$ and IFN- $\gamma$ were relatively evident in CD4+ (TNF-a, median: 2.2\%, range: 0-15.8\%; IFN-y, median: $8.2 \%$, range: $0.7-28.6 \%$ ) and CD8+ (TNF-a, median: $2.6 \%$, range: $0-14.4 \%$; IFN-ץ, median: $11.6 \%$, range: $0.6-$ $32.3 \%) \mathrm{T}$ cells in the patients. Secretion of IL-2 was restricted in the CD4 + subset (median: $2.8 \%$, range: $0-32.9 \%)$. The percentages of TNF-a-producing CD $4+$ T cells $(P=0.009)$, CD8 + T cells $(P<0.001)$, and NK cells $(P=0.002)$; IFN- $\gamma-$ producing CD8 + T cells $(P=0.002)$ and NK cells $(P=0.001)$; and IL-2-producing CD $4+\mathrm{T}$ cells $(P<0.001)$ and CD $8+\mathrm{T}$ cells $(P=0.005)$ were significantly lower in the patients compared with the control group. Significant differences between the three groups were seen in the IL-2-producing CD4 + T cells $(P=0.001)$, and TNF-a- $(P=0.004)$, IFN- $-(P=0.010)$, and IL-2producing $(P=0.018)$ CD $8+$ T cells (Fig. 3$)$.

\section{Discussion}

Our data clarify the clinicopathologic and immunological features in patients with anti-IFN-y Abs. We confirmed that the patients experienced recurrent infections, particularly NTM and skin dermatoses. An unspecific clinical presentation of 
primary DLBCL in the jejunum and NTM lymphadenitis without granuloma formation was observed. A high index suspicion of mycobacterial infection in such patients should be maintained. The T cells were activated and had lower ratios of RTE cells to naïve T cells, indicating a possible lower thymic output in these patients. The number of NK cells increased as in previous reports $[1,13]$, but the percentages of subsets expressing activating markers decreased. Furthermore, cytokine expression in T and NK cells was lower in the patients than in the control group.

The current understanding of immune dysfunction in patients with anti-IFN- $\gamma$ Abs is limited. In a study conducted by Browne et al., lymphocyte phenotyping showed a significantly decreased T cell percentage and naïve T lymphocytes, which was consistent with our results [1]. In addition, we found that the percentages of RTEs and naïve T cells decreased and those of activated $T$ cells increased. The dynamic changes in T cell subpopulations raises the question of whether decreased non-activated T cell subpopulations are age- or disease-related thymic impairments or just a dynamic fluctuation of $T$ cell subsets due to infection. A comparison of the ratio of RTE to naïve T subsets suggested that patients with anti-IFNY Abs would have low levels of RTEs in the peripheral T cell pool. This may affect the replenishment and diversity of T cells and result in a delayed regeneration of T cells with a broad TCR repertoire [16].

Furthermore, an increase in the expression of CD38 + HLA-DR + T cells was detected in the case group. High expression of $\mathrm{CD} 38+\mathrm{HLA}-\mathrm{DR}+\mathrm{CD} 4+$ and CD38 + HLA-DR + CD8 + T cell subsets, indicative of T cell activation, are well-known in viral and bacterial infections [17-19]. However, repetitive or prolonged antigen stimulation may induce the expression of exhaustion markers and decrease IFN- $\gamma$ production [20]. Wang et al. demonstrated that patients with fatal H7N9 outcomes displayed higher and prolonged expression of CD38 + HLA-DR + on CD8 + T cells than those who survived [18]. The majority of these activated T cells concurrently expressed high levels of PD-1 with minimal IFN- $y$ production. In addition, a delay of clonally expanded TCRaß clonotypes within CD38 + HLA-DR + CD $8+T$ cells was featured in fatal cases. Similarly, our data revealed high percentages of CD38 + HLA-DR + CD $4+$ and CD38 + HLA-DR + CD8 + T cells in the patients with anti-IFN- $\mathrm{Abs}$. These patients suffered from adult-onset immunodeficiency due to defects in IFN-y immune surveillance that may lead to recurrent infection. While the status of PD-1 expression was not examined, the decreased expression of intracellular cytokines in the disease group supported exhausted function in these T cells.

In agreement with previous studies, the number of NK cells increased in patients with anti-IFN-Y Abs [1, 13]. Chronic and repeating opportunistic infections may be the predominant cause for the increase in the number of NK cells. We further evaluated subpopulations and functional markers of NK cells. Two major NK subpopulations, CD56 bright and CD56 + CD16 + subsets, were decreased. Expression of CD57 increased. Moreover, the expression of NKp30 and NKp46 and the production of TNF- $a$ and IFN- $y$ was decreased in NK cells. Indeed, the CD56 + CD16 + NK cells with a high cytolytic potential were differentiated from the CD56 ${ }^{\text {bright }} \mathrm{NK}$ cells, which proliferate and produce IFN- $\gamma$ in response to stimulation [21, 22]. CD57 + cells are defined a subset of highly mature cells in the NK population [23]. The expression of activation receptors, including NKG2D, DAP10, CD16, natural cytotoxicity receptors (NKp30, NKp44, and NKp46), CD226, and 2B4 are downregulated during NK-cell maturation [24]. NK cells exhibiting impaired effector functions have also been reported in hosts with tumors or chronic infections [25]. NK cells with exhausted effector functions show decreased cytokine production and cytolytic activity. Altogether, these data indicate the exhausted immune status of NK cells in patients with anti-IFN-y Abs. Further studies are necessary to clarify the functional exhaustion in the expanded CD57 + subpopulation.

Studies on the ability of the lymphocyte subpopulations to produce cytokines in patients with anti-IFN- $\gamma$ Abs are limited. Anti-IFN-y Abs may block the production of downstream mediators of IFN-y activity. Krisnawati et al. reported a significant decrease in the levels of serum TNF- $a$ and IFN- $\gamma$ in all tested serum samples of patients with anti-IFN- $y$ Abs [12]. The production of IL-2 and TNF-a in CD4 + cells and TNF-a in CD8 + cells was significantly lower in a study conducted by Wipasa et al. [14]. The present study found similar results, with a decrease in cytokine production in the lymphocyte subpopulations. Although cytokine production varied a great deal in the patients, the observation of cytokine responses in resolved cases may account for immune exhaustion and lead to a higher risk of disseminated NTM or other opportunistic infections.

Page 10/16 


\section{Conclusions}

In conclusion, we reported the clinicopathologic features and the immune status of 20 patients with anti-IFN-y Abs. This study demonstrated that NTM-associated lymphadenitis could develop without granuloma formation, and that DLBCL could occur in an unusual site. Additionally, T cells were activated with decreased thymic output, and NK cells were highly matured with decreased expression of activation markers. The lymphocyte subpopulations had a reduction in cytokine responses, which is suggestive of the immune system being exhausted in these patients. We believe our study has shed light on the pathogenesis of the reported disease, which presents recurrent infection.

\section{Declarations}

Funding This study was supported by the Chang Gung Memorial Hospital (grant number CMRPG8K0341).

Acknowledgements We acknowledge Mr. Yu-Shiang Hu (senior product specialist, BD Biosciences, Taiwan) for help with the experimental setting, and Biostatistics Center, Kaohsiung Chang Gung Memorial Hospital for statistics work.

Conflicts of Interest The authors declare no competing interests.

Availability of data and material Upon request.

Code availability Upon request.

Authors' Contributions WTH conceptualized and designed the study. CLK and JYD designed and performed the experiments to detect neutralizing anti-IFN-y antibodies. WCH and HLY acquired the data. YCC, CHL, and WTH interpreted the data. YCC and WTH conducted the literature review and wrote the draft manuscript. SWW performed the statistical analysis. All authors critically reviewed and approved the final manuscript.

Ethics approval This study was approved by the Ethics Committee of the Chang Gung Memorial Hospital, Kaohsiung, Taiwan, in accordance with the Declaration of Helsinki (IRB201901509B0C501).

Consent to participate All participants provided written informed consent.

Consent for publication Obtained

\section{References}

1. Browne SK, Burbelo PD, Chetchotisakd P, Suputtamongkol Y, Kiertiburanakul S, Shaw PA, et al. Adult-onset immunodeficiency in Thailand and Taiwan. N Engl J Med. 2012;367(8):725-34.

2. Wu UI, Holland SM. Host susceptibility to non-tuberculous mycobacterial infections. Lancet Infect Dis. 2015;15(8):968-80.

3. Ku CL, Chi CY, von Bernuth H, Doffinger R. Autoantibodies against cytokines: phenocopies of primary immunodeficiencies? Hum Genet. 2020;139(6-7):783-94.

4. Shih HP, Ding JY, Yeh CF, Chi CY, Ku CL. Anti-interferon-gamma autoantibody-associated immunodeficiency. Curr Opin Immunol. 2021;72:206-14.

5. Hong GH, Ortega-Villa AM, Hunsberger S, Chetchotisakd P, Anunnatsiri S, Mootsikapun P, et al. Natural history and evolution of anti-interferon-gamma autoantibody-associated immunodeficiency syndrome in Thailand and the United States. Clin Infect Dis. 2020;71(1):53-62.

6. Jutivorakool K, Sittiwattanawong P, Kantikosum K, Hurst CP, Kumtornrut C, Asawanonda P, et al. Skin manifestations in patients with adult-onset immunodeficiency due to anti-interferon-gamma autoantibody: A relationship with systemic 
infections. Acta Derm Venereol. 2018;98(8):742-7.

7. Wu UI, Wang JT, Sheng WH, Sun HY, Cheng A, Hsu LY, et al. Incorrect diagnoses in patients with neutralizing antiinterferon-gamma-autoantibodies. Clin Microbiol Infect. 2020;26(12):1684:e1-e6.

8. Chawansuntati K, Rattanathammethee K, Wipasa J. Minireview. Insights into anti-interferon-gamma autoantibodies. Exp Biol Med (Maywood). 2021;246(7):790-5.

9. Koizumi Y, Mikamo H. Anti-Interferon-gamma autoantibody and disseminated nontuberculous mycobacteria infection. What should be done to improve its clinical outcome? Clin Infect Dis. 2021;72(12):2209-11.

10. Chi CY, Lin CH, Ho MW, Ding JY, Huang WC, Shih HP, et al. Clinical manifestations, course, and outcome of patients with neutralizing anti-interferon-gamma autoantibodies and disseminated nontuberculous mycobacterial infections. Med (Baltim). 2016;95(25):e3927.

11. Guo J, Ning XQ, Ding JY, Zheng YQ, Shi NN, Wu FY, Lin YK, Shih HP, Ting HT, Liang G, et al. Anti-IFN-gamma autoantibodies underlie disseminated Talaromyces marneffei infections. J Exp Med. 2020, 217(12).

12. Krisnawati DI, Liu YC, Lee YJ, Wang YT, Chen CL, Tseng PC, et al. Functional neutralization of anti-IFN-gamma autoantibody in patients with nontuberculous mycobacteria infection. Sci. Rep.2019:9(1):5682.

13. Chruewkamlow N, Mahasongkram K, Pata S, Chaiwarith R, Salee P, Supparatpinyo K, et al. Immune alterations in patients with anti-interferon-gamma autoantibodies. PLOS ONE. 2016;11(1):e0145983.

14. Wipasa J, Wongkulab P, Chawansuntati K, Chaiwarit R, Supparatpinyo K. Cellular immune responses in HIV-negative immunodeficiency with anti-interferon-gamma antibodies and opportunistic intracellular microorganisms. PLOS ONE. 2014;9(10):e110276.

15. Boldt A, Borte S, Fricke S, Kentouche K, Emmrich F, Borte M, et al. Eight-color immunophenotyping of T-, B-, and NK-cell subpopulations for characterization of chronic immunodeficiencies. Cytometry B Clin Cytom. 2014;86(3):191-206.

16. Moore JW, Beattie L, Osman M, Owens BM, Brown N, Dalton JE, et al. CD4 + recent thymic emigrants are recruited into granulomas during Leishmania donovani infection but have limited capacity for cytokine production. PLOS ONE. 2016;11(9):e0163604.

17. Lim A, Allison C, Tan DB, Oliver B, Price P, Waterer G. Immunological markers of lung disease due to non-tuberculous mycobacteria. Dis Markers. 2010;29(2):103-9.

18. Wang Z, Zhu L, Nguyen THO, Wan Y, Sant S, Quiñones-Parra SM, et al. Clonally diverse CD38 + HLA-DR + CD8 + T cells persist during fatal H7N9 disease. Nat Commun. 2018;9(1):824.

19. Gonzalez SM, Taborda NA, Rugeles MT. Role of different subpopulations of CD $8+T$ cells during HIV exposure and infection. Front Immunol. 2017;8:936.

20. Fink PJ. The biology of recent thymic emigrants. Annu Rev Immunol. 2013;31:31-50.

21. Michel T, Poli A, Cuapio A, Briquemont B, Iserentant G, Ollert M, et al. Human CD56bright NK cells: an update. J Immunol. 2016;196(7):2923-31.

22. Batoni G, Esin S, Favilli F, Pardini M, Bottai D, Maisetta G, et al. Human CD56 $6^{\text {bright }}$ and CD56 dim natural killer cell subsets respond differentially to direct stimulation with Mycobacterium bovis bacillus Calmette-Guerin. Scand J Immunol. 2005;62(6):498-506.

23. Lopez-Vergès S, Milush JM, Pandey S, York VA, Arakawa-Hoyt J, Pircher $H$, et al. CD57 defines a functionally distinct population of mature NK cells in the human CD56 dim CD16 + NK-cell subset. Blood. 2010;116(19):3865-74.

24. Long EO, Kim HS, Liu D, Peterson ME, Rajagopalan S. Controlling natural killer cell responses: integration of signals for activation and inhibition. Annu Rev Immunol. 2013;31:227-58.

25. Bi J, Tian Z. NK cell exhaustion. Front Immunol. 2017;8:760.

26. Li WS, Huang WC, Ku CL, Lee CH. Osteolytic lesions resulting from opportunistic infections. Kaohsiung J Med Sci. 2017;33(7):365-66.

Page 12/16 
27. Liu TT, Weng SW, Wang MC, Huang WT. Nontuberculous mycobacterial infection with concurrent IgG4-related lymphadenopathy. APMIS. 2016;124(3):216-20.

\section{Figures}

\section{Figure 1}

Histopathologic features in patients with anti-IFN-y autoantibodies. Representative hematoxylin and eosin (H\&E) staining of the skin biopsy shows subcorneal and intraepidermal collection of neutrophils (a), a dense neutrophilic infiltration in the dermis (b), granulomatous inflammation (c), erythema nodosum featuring both septal and lobular infiltrates of lymphocytes, neutrophils, histiocytes, eosinophils, and granulomas with giant cells (d,e), and erythema induratum characterized by predominant lobular panniculitis with histiocytes forming granulomas, necrosis, and vasculitis (f). Histologic features of the lymph node reveal necrotizing granulomatous inflammation (g), vague granulomas (h), and atypical lymphoid proliferation (inset figure) with thickened capsule (i). The computed tomography scan with intravascular contrast enhancement in case 8 shows spiculated wall thickening of the jejunum (arrow) with small bowel obstruction (j). The H\&E staining demonstrates transmural involvement of the bowel wall $(\mathrm{k})$ by infiltrates of large lymphoid cells $(\mathrm{I})$, which shows positive CD20 staining (m). 
a

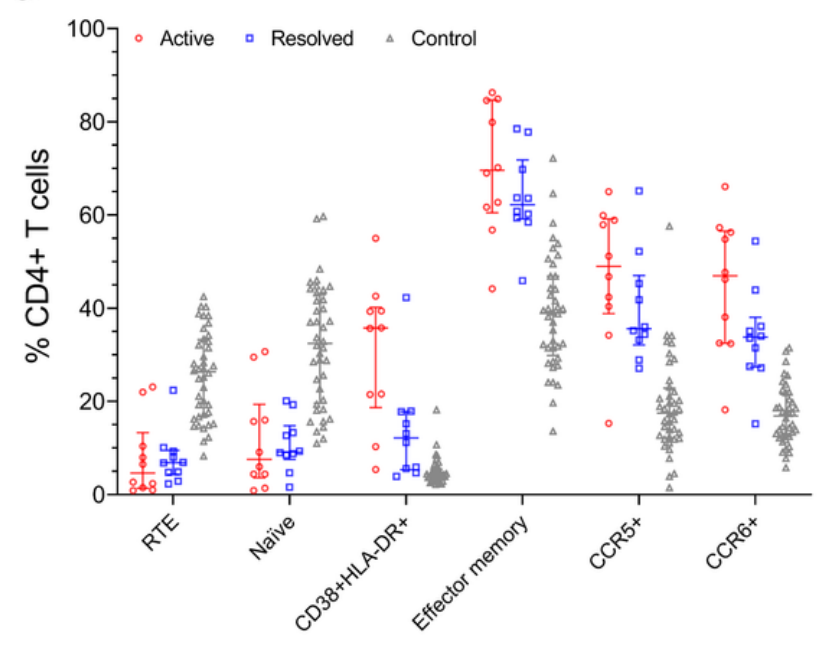

b
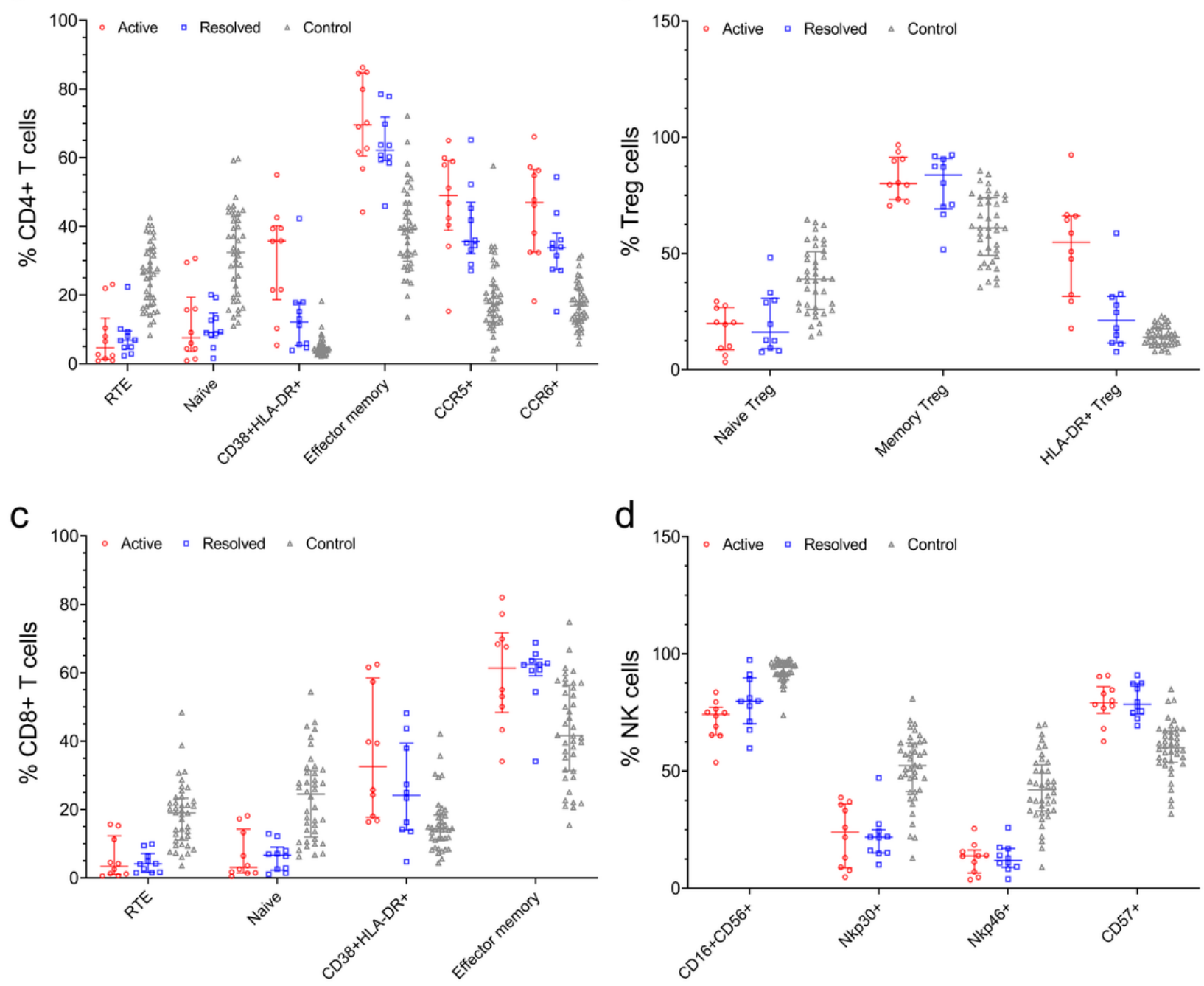

d

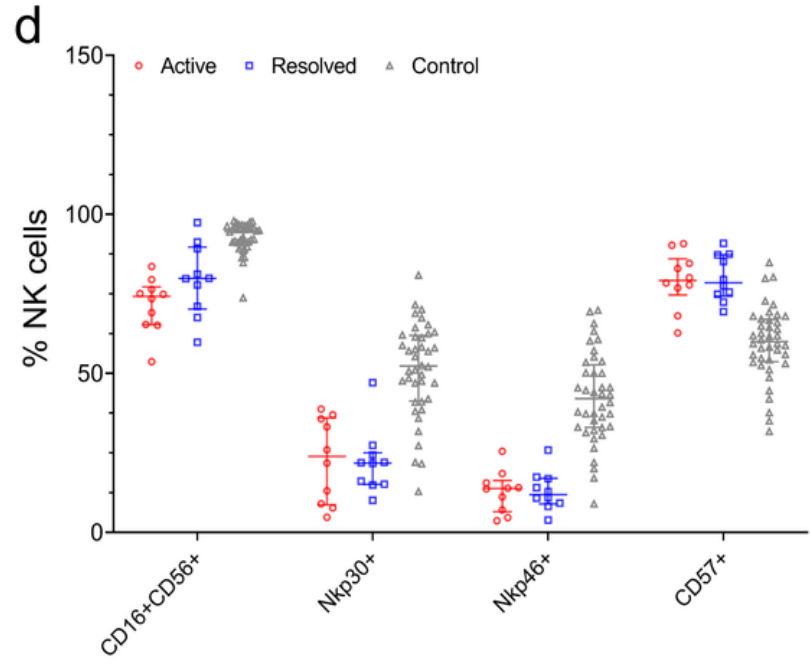

Figure 2

Comparison of lymphocyte subpopulations between the case and control groups. Dot plots are representative of the percentages of CD4+ T (a), Treg (b), CD8+ T (c), and NK cell subsets (d). The lymphocyte subpopulations with a P-value < 0.001 between the groups are shown. CCR, C-C chemokine receptor; NK, natural killer; RTE, recent thymic emigrants; TEM, effector memory $\mathrm{T}$ cell; Treg, regulatory $\mathrm{T}$ 

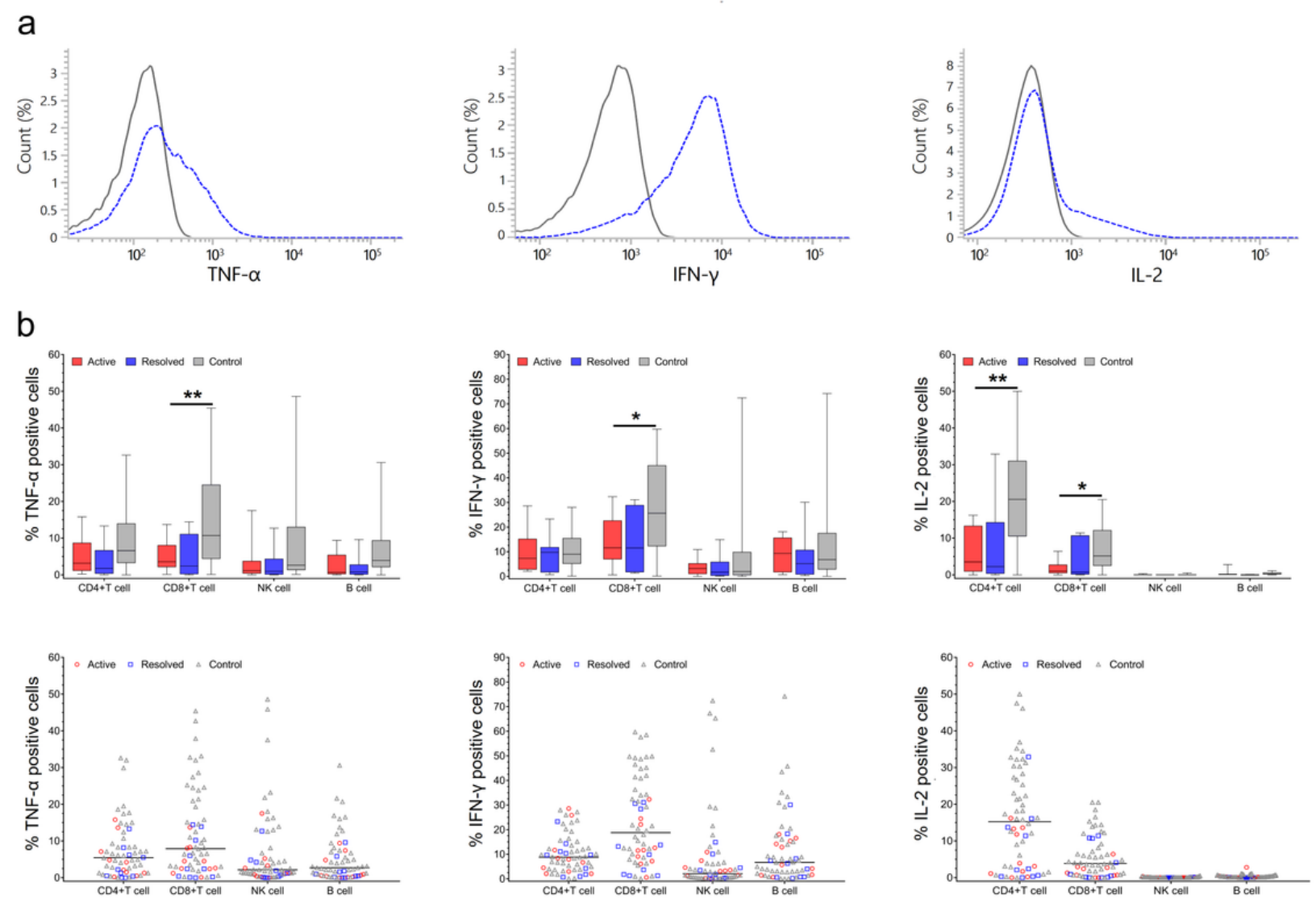

\section{Figure 3}

Intracellular cytokine production in patients with anti-IFN-y auto-antibody and healthy subjects. Peripheral blood mononuclear cells (PBMCs) were stimulated with a leukocyte activation cocktail. The PBMCs were then stained using APCH7 conjugated anti-CD45 antibody, FITC conjugated anti-CD3 antibody, BV421 conjugated anti-CD4 antibody, APC conjugated anti-CD8 antibody, PE-Cy7 conjugated anti-CD16/anti-CD56 antibodies, PE-conjugated anti-TNF-a antibody, PerCP-Cy5.5 conjugated anti-IFN-y antibody, and BV510 conjugated anti- IL-2 antibody. The upper panel is representative of figures of the cytokine production in $\mathrm{CD} 8+\mathrm{T}$ cells (a). The increase in the cytokine production in response to the stimulant (blue dash curve) compared to the baseline with no stimulant (gray solid curve) was calculated. The results are represented as a percentage of lymphocytes with the fluorescent intensity higher than that of the baseline (b). The comparison data are

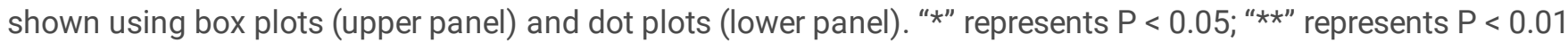

\section{Supplementary Files}


This is a list of supplementary files associated with this preprint. Click to download.

- FigureS1Yaver.01.docx

- SupplementaryFigure2Legend.docx

- Supplementaryfigure2.tif

- Supplementarytable.docx 